\title{
Comparison of capacity models of different theoretical settings on the example of a small city roundabout in the City of Mostar
}

\author{
Danijela Maslać \\ University of Mostar, Faculty of Civil Engineering, B.S.C.E. \\ danijela.maslac@gf.sum.ba \\ Dražen Cvitanić \\ University of Split, Faculty of Civil Engineering, Architecture and Geodesy, Ph.D C.E. \\ drazen.cvitanic@gradst.hr
}

\begin{abstract}
Many roundabout capacity models are present in the world and they are classified into three key groups: empirical models, theoretical models, and microscopic simulation models. In Bosnia and Herzegovina and the Republic of Croatia, there is no roundabout capacity model prescribed by a rulebook. Theoretical capacity models are derived from gap acceptance theory. Due to some deficiencies of gap acceptance theory, Brilon and $\mathrm{Wu}$ introduce a new concept for analyzing the capacity of unsignalized intersections, and thereby of roundabouts too, based on conflict theory and queuing theory. This paper analyzes three roundabout capacity models most commonly used in the world (HCM, Akcelik, Brilon-Wu), with different theoretical backgrounds, in order to compare them with directly measured capacity in the field in local conditions in Bosnia and Herzegovina and thus to see the differences in application results.
\end{abstract}

Keywords: capacity, roundabouts, direct capacity measurement

\section{Usporedba modela kapaciteta različitih teorijskih postavki na primjeru malog gradskog kružnog raskrižja u gradu Mostaru}

Sažetak: U svijetu postoji veliki broj modela kapaciteta kružnih raskrižja koji su svrstani u tri ključne skupine: empirijski modeli, teoretski modeli i mikroskopski simulacijski modeli. U Bosni i Hercegovini i Republici Hrvatskoj ne postoji pravilnikom propisani model kapaciteta kružnih raskrižja. Teoretski modeli kapaciteta izvedeni su iz teorije prihvaćanja vremenskih praznina. Zbog određenih nedostataka teorije prihvaćanja vremenskih praznina Brilon i Wu uvode novi koncept za analizu kapaciteta nesemaforiziranih raskrižja, pa time i kružnih raskrižja, zasnovan na teoriji konflikata i teoriji repova (queuing theory). U ovom radu se analiziraju tri najčešće korištena modela kapaciteta kružnih raskrižja u svijetu (HCM, Akcelik, Brilon-Wu), s različitim teorijskim pozadinama, kako bi se usporedili s direktno mjerenim kapacitetom na terenu u lokalnim uvjetima u Bosni i Hercegovini i time uvidile razlike $u$ rezultatima primjene.

Ključne riječi: kapacitet, kružna raskrižja, direktno mjerenje kapaciteta

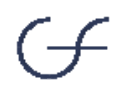


Maslać, D., Cvitanić, D.

Comparison of capacity models of different theoretical settings on the example of a small city roundabout in the City of Mostar

\section{INTRODUCTION}

Roundabouts are classified as unsignalized intersections. The minor stream vehicles coming to the roundabout entry must give way to vehicles that are already in the roundabout (priority stream) [1]. [2]:

The capacity of a roundabout is obtained by summing the capacities of all approaches

$$
c=\sum c_{i}
$$

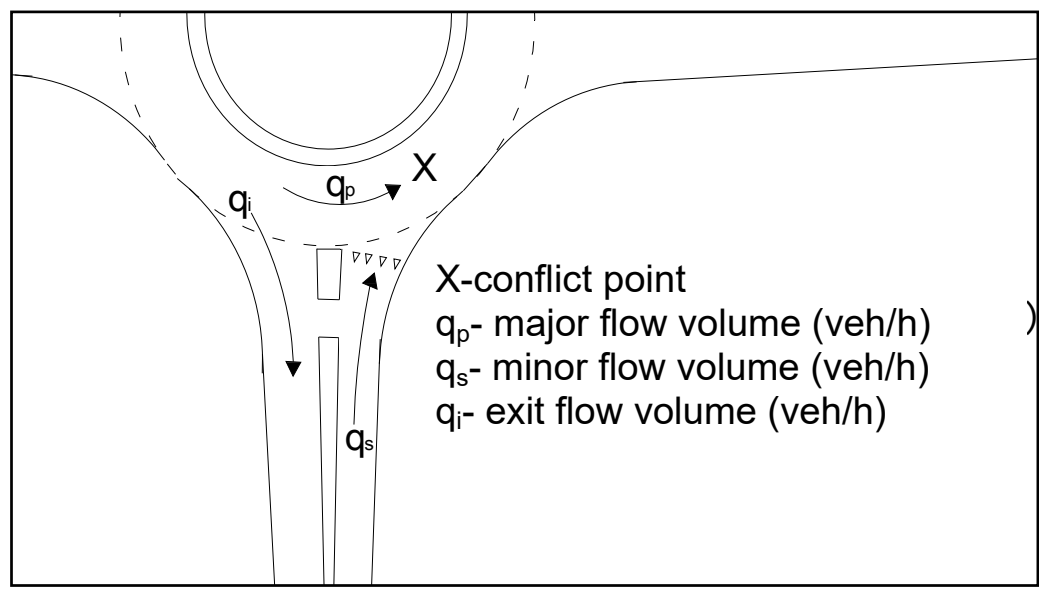

Figure 1. Determining the roundabout approach capacity

The capacity of approach $\left(c_{i}\right)$ is defined at the stop line, where traffic streams interact, and is reached when the capacity of the most saturated lane is reached. It is a function of traffic volumes of entry lane $\left(q_{s}-\right.$ minor stream $)$, roundabout $\left(q_{p}\right.$ - priority stream) and exit lane $\left(q_{i}\right)$. Traffic volume is determined by counting traffic at an existing roundabout or by forecasting traffic for new roundabouts.

The capacity of a roundabout is significantly influenced by the presence of pedestrians and cyclists and weather conditions, as well as the driver behavior [2].

There are many roundabout capacity models in the world, which are classified into three key groups, empirical models (based on measurements of actual capacity of intersections in saturated flow conditions), theoretical models derived from gap acceptance theory and microscopic simulation models based on modeling of driver behavior, kinematics and vehicle interactions [3]. Gap acceptance theory is used to describe acceptance of time gaps between vehicles in the major stream by vehicles from the minor approach, from which the capacity of unsignalized intersections, and thereby of roundabouts too, is derived. The model parameters are mainly adapted to the conditions of the country they originate from and need to be calibrated in local conditions.

In Bosnia and Herzegovina, there is no roundabout capacity model prescribed by rulebooks, so designers can choose the desired model.

In this paper, the three most commonly used roundabout capacity models (HCM 2010, Akcelik, Brilon-Wu) are analyzed and the obtained values are compared with the capacity 
Maslać, D., Cvitanić, D.

Comparison of capacity models of different theoretical settings on the example of a small city roundabout in the City of Mostar

measured in local conditions. The theoretical background of the selected models differs, which is presented in more detail in Chapter 2.

There are two basic capacity measurement methods [4]:

$>$ direct measurement method and

$>$ indirect measurement method

The direct roundabout capacity measurement method involves counting the traffic volume of entry flow and conflicting flow in saturated flow conditions at 1-2 minute intervals. The curve of approach capacity with respect to conflict flow of the roundabout is obtained by regression analysis. Direct capacity measurement provides more accurate results for the observed intersection.

Indirect measurement method involves capacity estimation by certain theoretical models, but with calibration of key traffic flow parameters.

Directly measured capacity is used here to test selected capacity models.

\section{THEORETICAL BACKGROUND OF SELECTED ANALYTICAL MODELS}

\subsection{Model HCM 2010 (American model)}

The U.S. HCM 2010 single-lane roundabout capacity model, defined by expression (2.1), was established as an exponential regression model based on experimental research in the U.S. [5]:

$$
c=1130 e^{\left(-1.0 \times 10^{-3} v_{c}\right)}
$$

It is evident from expression (2) that this form of model requires only data on the traffic volume of the major (conflicting) flow. Due to the possibility of adjustment to local conditions, HCM 2010 generalizes the form of the capacity expression by introducing theoretical parameters of the model, which results in the following expression:

$$
c=A e^{\left(-B v_{c}\right)}
$$

where:

$A=\frac{3600}{t_{f}}, B=\frac{t_{c}-\left(\frac{t_{f}}{2}\right)}{3600}$

$v_{c}$ - is the conflicting flow (within the roundabout) (veh/h)

$t_{c}$-is the critical headway (s) and $t_{f}$-is the follow-up headway (s)

Thus, the HCM 2010 model can be calibrated using only two parameters: critical headway $t_{c}$ and follow-up headway $t_{f}$ [5].

The HCM 2010 single-lane roundabout capacity model has the form of the Siegloch M1 capacity model (from the group of gap-acceptance based models) [6], [7], which is defined by the expression: 
Maslać, D., Cvitanić, D.

Comparison of capacity models of different theoretical settings on the example of a small city roundabout in the City of Mostar

$$
C=\frac{e^{-q_{p}\left(t_{c}-\frac{t_{f}}{2}\right)}}{t_{f}}
$$

The assumption is that vehicles move at the desired speed without interdependence, vehicles arrive according to the Poisson distribution, and the distribution of major flow headways is negative exponential [7], [8]. Table 1 shows the values of model parameters.

Table 1. Calibration parameters of HCM 2010 for the U.S. [9]

\begin{tabular}{|c|c|c|}
\hline & $t_{c}$ - critical headway (s) & $t_{f}$ - follow-up headway (s) \\
\hline Model HCM 2010 & 5.19 & 3.20 \\
\hline Model HCM 2016 & 4.98 & 2.61 \\
\hline
\end{tabular}

\subsection{Model Akcelik (Australian model)}

The model developed in Australia is based on gap acceptance theory for roundabouts, and was initially introduced in the form of a model called SR45 [10]:

$c=\frac{\varphi Q_{c} e^{-\lambda\left(t_{c}-\Delta\right)}}{1-e^{-\lambda t_{f}}}$

Regression equations for critical headways $\left(t_{c}\right)$ and follow-up headways $\left(t_{f}\right)$ of major and minor flows were developed using data from 55 roundabouts in Australia [10].

The SIDRA model (Akcelik \& Associates Pty Ltd., 2013) represents a further development of the SR45 model. It was developed using an analogy of the operation of signalized intersections [11] and a revised version of the empirical follow-up headway and critical gap equations from SR45:

$c=\frac{3600}{\beta}\left(1-\Delta_{c} \frac{q_{c}}{3600}+0.5 \beta \varphi_{c} \frac{q_{c}}{3600}\right) e^{-\lambda\left(\alpha-\Delta_{c}\right)}$

where:

$\alpha$ - is the critical headway (s)

$\beta$ - is the follow-up headway (s)

$\Delta_{\chi}$ - is the minimum headway in the major stream (for single-lane roundabouts $\Delta_{\chi}=2 \mathrm{~s}$ )

Sensitivity to traffic and geometric parameters resulted in a complex model, but each part of the model can be understood through gap acceptance theory.

The model equation is best explained by comparing the approach capacity of a roundabout with the approach capacity of a signalized intersection as shown in Figure 2, [12].

Capacity $(c)$ is proportional to the value of saturated flow (s) and the ratio of effective green time $(g)$ to cycle time $(C)$, resulting in the equation: $\mathrm{c}=\mathrm{s}(\mathrm{g} / \mathrm{C})$.

For roundabouts, the $g / C$ ratio is analogous to the effective unblocked time when vehicles can enter the roundabout. 
Maslać, D., Cvitanić, D.

Comparison of capacity models of different theoretical settings on the example of a small city roundabout in the City of Mostar

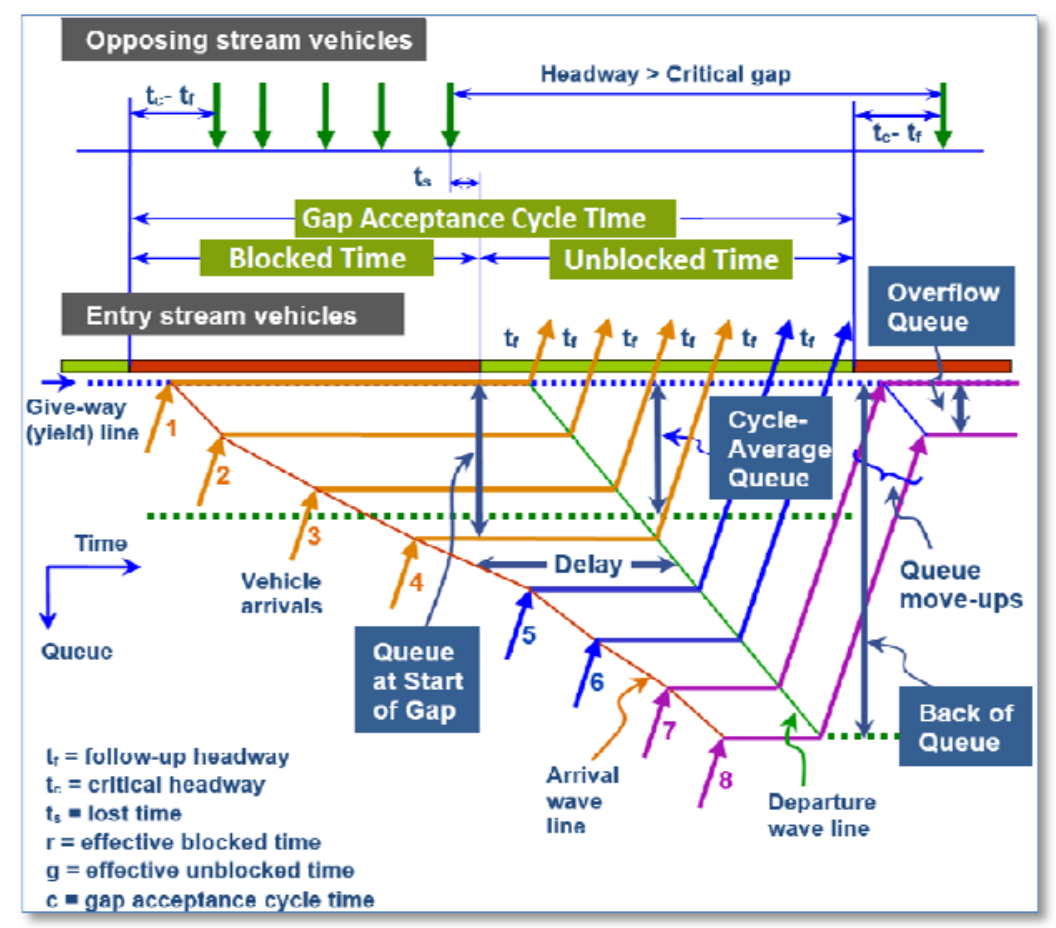

Figure 2. Illustration of the analogy of a signalized intersection for the roundabout gap acceptance model [11]

The gap acceptance cycle time within the major stream is divided analogously to the cycle time (C) of a signalized intersection consisting of effective green (g) and effective red (r) times in [11]:

- $\quad\left(t_{b}\right)$ blocked period; vehicles waiting due to lack of an acceptable gap analogous to red time $(r)$

- $\quad\left(t_{u}\right)$ unblocked period; vehicles enter when an acceptable gap occurs -

Where: analogous to green time $(\mathrm{g})$.

$t_{b}=\frac{e^{\lambda\left(\alpha-\Delta_{m}\right)}}{\varphi_{m} q_{m}}-\frac{1}{\lambda}$ (seconds)

$t_{u}=\frac{1}{\lambda}$ (seconds)

$C=t_{b}+t_{u}$ (seconds)

or: $C=r+g$ (seconds)

$r, g$ - effective red and green periods in the major stream (seconds)

\subsection{Model Brilon-Wu (German model)}

Gap acceptance theory is used to describe acceptance of time gaps between vehicles in the major stream by vehicles from the minor approach [12], from which the capacity of unsignalized intersections, and thereby of roundabouts too, is derived. 
Maslać, D., Cvitanić, D.

Comparison of capacity models of different theoretical settings on the example of a small city roundabout in the City of Mostar

According to Brilon and Wu [12], [13] possible key disadvantages of gap acceptance theory are:

$>$ Determining or estimating the critical headway is a challenging procedure. Estimating $t_{c}$ is a source of uncertainty within gap-acceptance based capacity models.

$>$ Although this methodology is theoretical it is based on quite pragmatic simplifications.

$>$ Gap acceptance theory does not really work if drivers do not comply with the rules, or if there is a change in the priority of traffic flows.

$>$ The theory completely loses its applicability when it comes to pedestrians and cyclists. Namely, for pedestrians, at least on the European continent, rather complicated priority rules apply, such that pedestrians and cyclists sometimes have the right of way, and sometimes not.

Due to the aforementioned shortcomings of gap acceptance theory, Brilon and Wu [14] describe a concept for analyzing the capacity of unsignalized intersections, and thereby of roundabouts too, based on queuing theory and conflict theory. Conflict points of intersection are analyzed and each conflict point can be analyzed through queuing theory [14], [15]. Vehicles arriving to the approach and waiting to enter the roundabout can also be modeled as a queuing system. According to the concept of queuing theory, vehicles are elements queuing until they reach the first position of the queue, and then wait for service. Thus, the total average vehicle delay consists of queuing and waiting at the intersection stop line [8]. Queue is a line of vehicles on a minor approach, and the first position of the queue is the stop line of the intersection. In the process, the measure of arrival in the system is the quantity of the traffic flow, and the measure of departure from the system is the capacity of minor approach.

According to conflict theory introduced by Brilon and Wu [14], an intersection is observed as a system where the probability of predetermined states (occurrence of a queue, a platoon, a single vehicle or free space) in the major stream is determined, and then the capacity of a minor stream depends solely on the probability of the state of free space (unblocked minor stream vehicles).

The simplest example to understand is a conflict of two streams (major $i$, minor $j$ ) as shown in Figure 3, which corresponds to the situation of a single-lane roundabout.

A conflict area is assumed to be comparable to a queuing system [13], [14].

A conflict point can be occupied by a major stream vehicle in three different ways: it is occupied if there is a queue, a platoon, or a single arriving vehicle. A minor stream vehicle can only pass the conflict point if the conflict point is neither occupied by a queue nor by a platoon nor by a single arriving vehicle in the major stream [14].

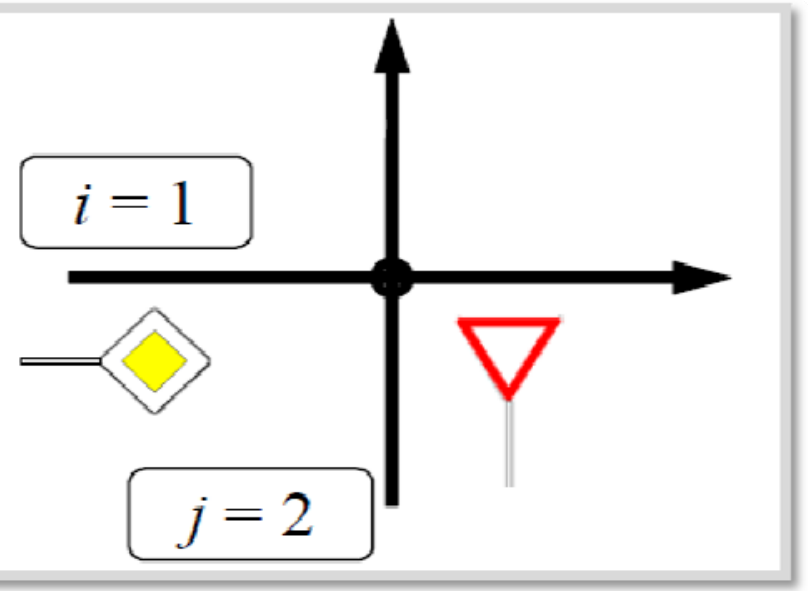

Figure 3. A system with one major and one minor stream, which is transferred to a roundabout [14] 
Maslać, D., Cvitanić, D.

Comparison of capacity models of different theoretical settings on the example of a small city roundabout in the City of Mostar

To pass the intersection, vehicles of both streams must pass the conflict point, and the total time available for vehicles from both streams is 3600 seconds.

$3600=q_{1} \cdot t_{B, 1}+c_{2} \cdot t_{B, 2}$

where:

$q_{1}$ - is the traffic volume of the major stream i (veh/h)

$c_{2}$ - is the capacity of the minor stream $\mathrm{j}(\mathrm{veh} / \mathrm{h})$

$t_{B, i}$ - is the service time for stream i (s)

with the condition:

$q_{1} \cdot t_{B, 1} \leq 3600$

Here, the capacity of the minor stream $\mathrm{j}$ is:

$C_{2}=\frac{3600-q_{1} \cdot t_{B, 1}}{t_{B, 2}}=\frac{3600}{t_{B, 2}} \cdot\left(1-\frac{q_{1} \cdot t_{B, 1}}{3600}\right)=c_{\max , 2} \cdot\left(1-B_{1}\right)=c_{\max , 2} \cdot p_{0,1}$

where:

$B_{1}=\frac{q_{i} \cdot t_{B, i}}{3600}$ - occupancy of the conflict area by stream i

$p_{0,1}=1-B_{1}-$ probability that the conflict area is not occupied by stream i

$c_{\max , j}=\frac{3600}{t_{B, i}}-$ maximum capacity in case of no conflicting stream $\mathrm{i}$

Minor stream vehicles can only pass the conflict area if no vehicle uses the conflict area.

The probability that the conflict area is occupied by a major stream vehicle i depends on the size of the major stream $q_{i}$ :

$$
p(x)=\frac{1}{3600} \cdot q_{i} \cdot t_{i}
$$

in which

$t_{i}$ - is the time the conflict area is occupied by vehicle $\mathrm{i}$

$1-p(x)$ - the probability that the conflict area is not occupied by a major stream vehicle i

For a minor stream vehicle waiting to enter the intersection, the conflict area is also blocked if a major stream vehicle is approaching the conflict area. Thus, the probability that the conflict area is not occupied by an arriving major stream vehicle is:

$$
p_{a}(x)=e^{\left(-\frac{1}{3600} \cdot q_{p} \cdot t_{c}\right)}
$$

assuming that the major stream gaps are exponentially distributed.

So, a minor stream vehicle can only enter the intersection if both of the following conditions are met: 
Maslać, D., Cvitanić, D.

Comparison of capacity models of different theoretical settings on the example of a small city roundabout in the City of Mostar

- $\quad$ if the conflict area is not occupied by the major stream

- $\quad$ if no major stream vehicle is approaching the intersection.

Wu [14] proposed the following model for single-lane roundabouts:

$C=\left(1-\frac{\tau q_{c}}{3600}\right) \frac{3600}{t_{f}} \cdot \exp -\left(\frac{q_{c}}{3600}\right)\left(t_{c}-\frac{t_{f}}{2}-\tau\right)$

where:

$\mathrm{C}$ is the minor stream capacity (veh/h)

$\tau$ is the minimum headway between vehicles in the roundabout (s)

$q_{c}-$ is the traffic volume in the roundabout $(v e h / h)$

The advantage of the model is in the application of the Cowan (bunched) exponential distribution $\mathrm{M} 3$, which more realistically describes headways in the major stream.

According to the Brilon-Wu model, the calibration parameters are not fixed and they depend on the intersection geometry.

By applying conflict theory, there is a possibility to analyze the influence of pedestrians, which is very important in populated areas [14], [15].

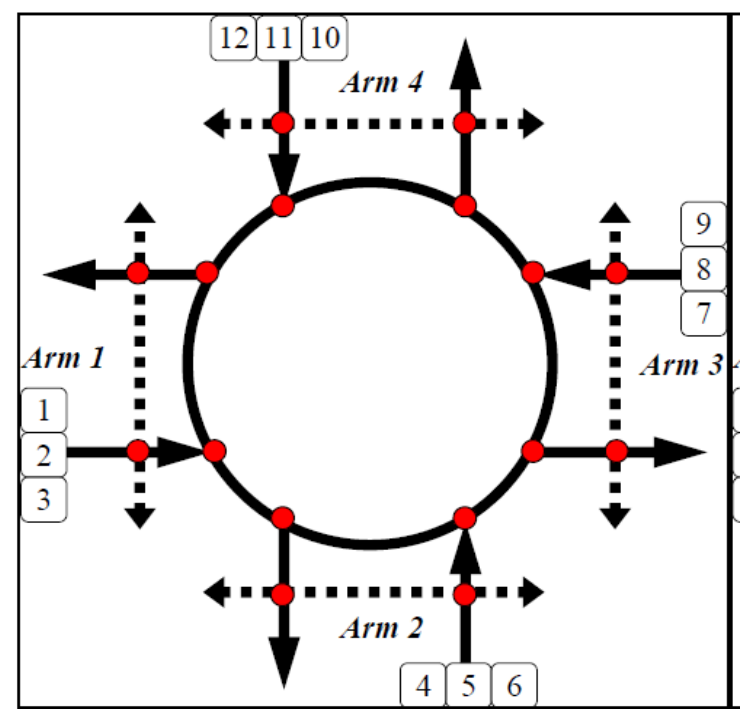

Figure 4. Conflict points on a single-lane roundabout [14] 
Maslać, D., Cvitanić, D.

Comparison of capacity models of different theoretical settings on the example of a small city roundabout in the City of Mostar

\section{APPLICATION OF CAPACITY MODELS IN LOCAL CONDITIONS (MOSTAR)}

This chapter presents a comparison of the results of capacity assessment with selected models calibrated in local conditions at a small urban roundabout with directly measured capacity in the field. The intersection is located in the city of Mostar, and its diameter is $22 \mathrm{~m}$.

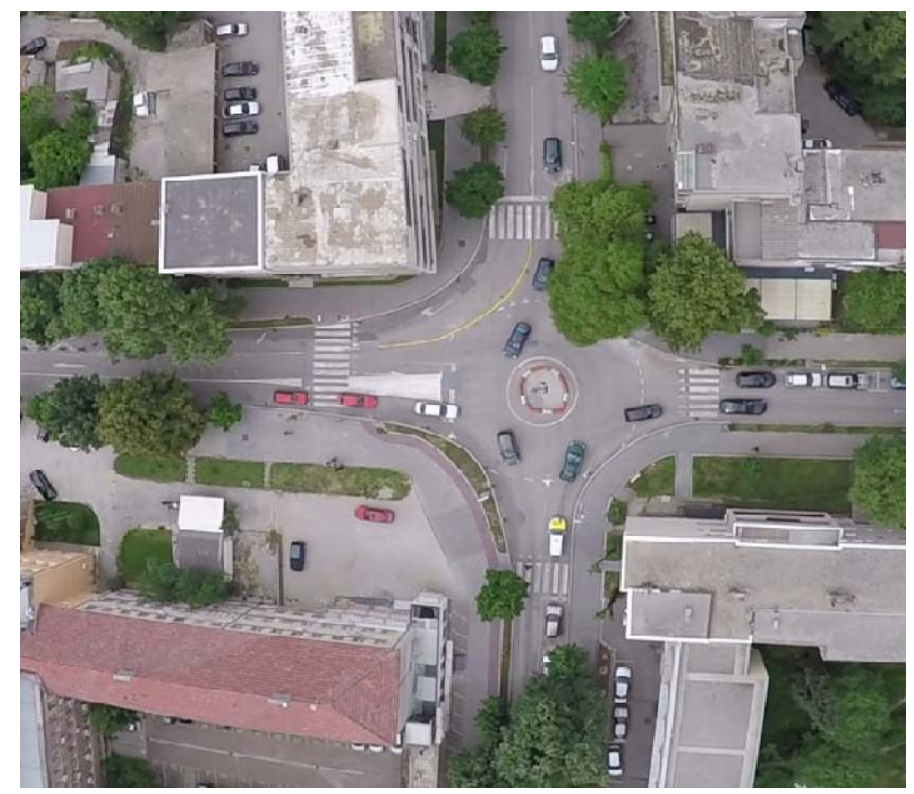

Figure 5. Subject roundabout, City of Mostar

At the subject roundabout, a direct measurement of capacity in saturated conditions was performed by counting vehicles in one-minute intervals.

The results of the direct measurement of the roundabout approach capacity are shown in the scatter diagram in Figure 6. The exponential curve describes the measured data well, which is confirmed by the coefficient of determination $R^{2}=0.758$. The equation of directly measured capacity is:

$$
y=1235,9 \cdot e^{-0,001 x},
$$

or

$$
C=1235,9 e^{\left(-0,001 q_{c}\right)},
$$

where $c$ is the capacity $(v e h / h)$ and $q_{c}$ is the conflicting flow (veh/h). 
Maslać, D., Cvitanić, D.

Comparison of capacity models of different theoretical settings on the example of a small city roundabout in the City of Mostar

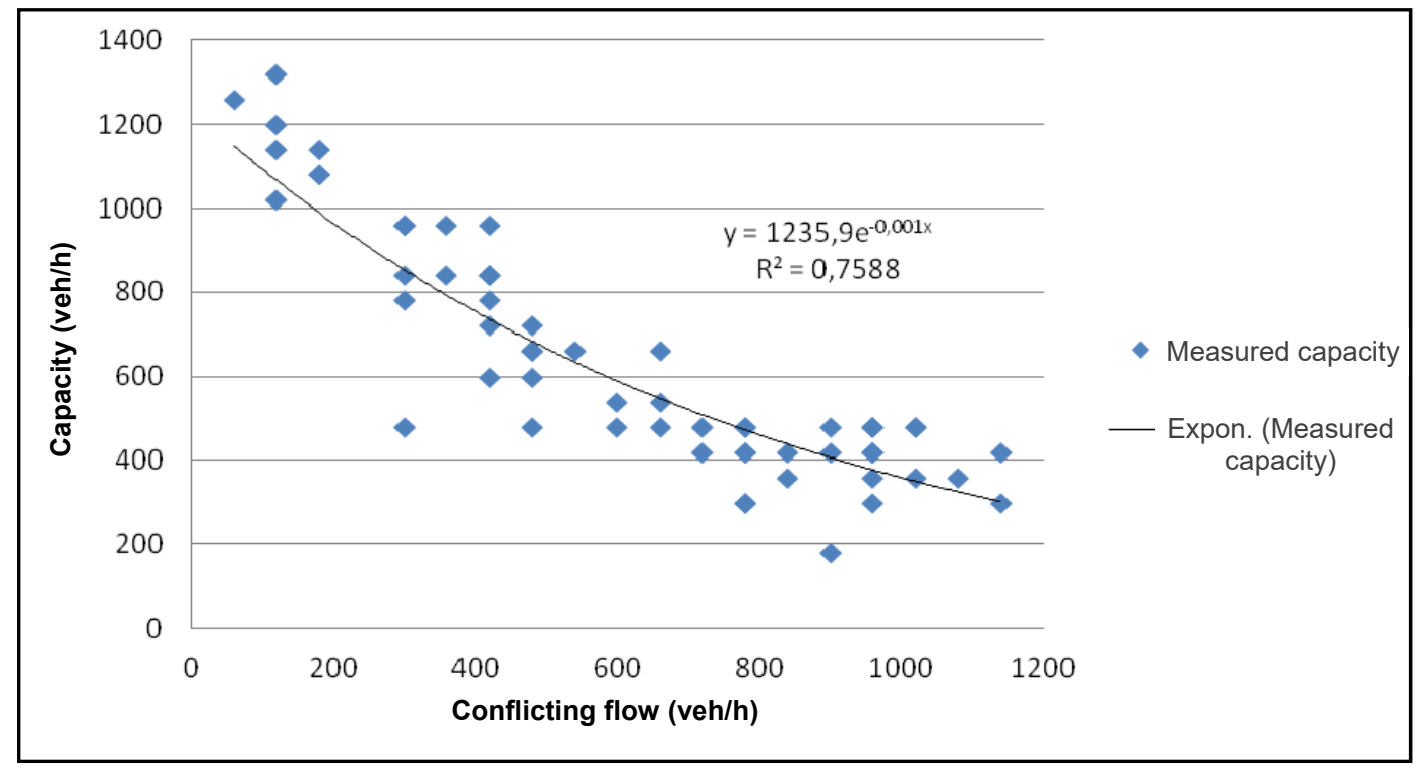

Figure 6 . The capacity directly measured at the subject intersection

Calibration of the necessary parameters for the selected capacity models was carried out and the following values were obtained [19]:

$>$ critical headway $t_{c}=4.46 \mathrm{~s}$ (estimation was made using Wu method)

$>$ follow-up headway $t_{f}=2.9 \mathrm{~s}$ (measured directly in the field).

The value of the minimum time gap within the major stream $\Delta$ was not determined, but the value $\Delta=2.3 \mathrm{~s}$, recommended according to the Brilon-Wu model, and $\Delta=2 \mathrm{~s}$, according to the Akcelik model, were used.

For the HCM 2010 model (according to expression 2), the parameter values $A=1241.5$ and $B=0.000861$ were obtained.

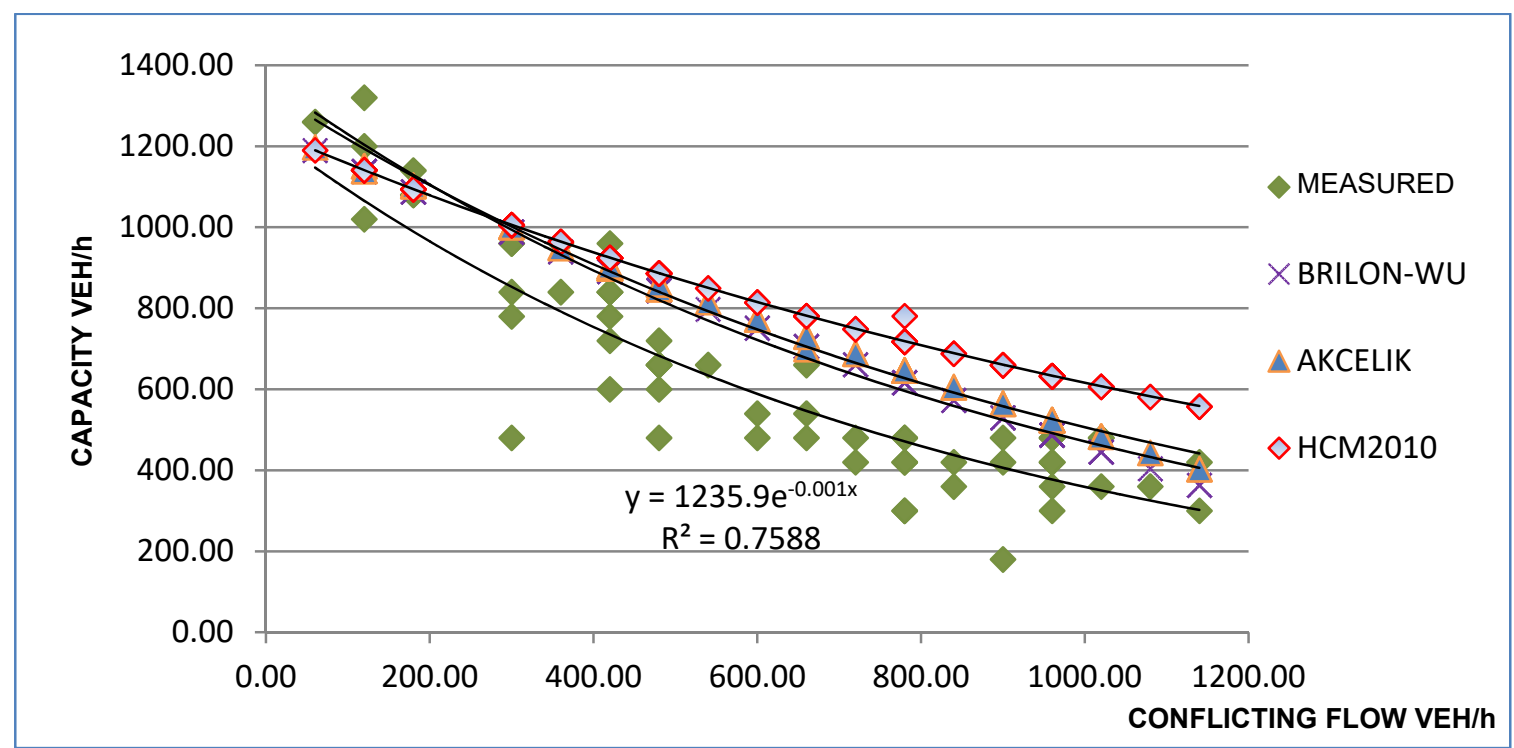

Figure 7. Comparison of selected calibrated models (HCM 2010, Akcelik and Brilon-Wu) and directly measured capacity for a small urban roundabout in the City of Mostar 
Maslać, D., Cvitanić, D.

Comparison of capacity models of different theoretical settings on the example of a small city roundabout in the City of Mostar

The results of calibrated capacity models in relation to capacity directly measured in the field are shown in Figure 7.

The largest deviation from the directly measured field capacity is observed from the graph for the HCM 2010 model. Namely, the HCM 2010 model was established as an exponential regression model in U.S. conditions, and it is hardly adaptable to other country conditions. It has the form of the theoretical Siegloch M1 model.

M1 distribution of time gaps within a major stream does not have a possibility to describe a platoon in the major stream, and therefore large deviations in the zone of large conflict flow are particularly prominent. It can be concluded that the reliability of this model in local conditions very much depends on the traffic volume of the major and minor stream, and that it can be accepted in local conditions only in a very small range of volumes, conflict flow of 0-200 veh/h and major stream flow (1000-1200 veh/h).

Deviations are significantly smaller in the Akcelik model and the Brilon-Wu model, they are easier to adapt to local conditions. The advantage of the models is also in the application of the Cowan M3 distribution, which better describes time gaps in the major stream.

The graph shows that the Akcelik model and the Brilon-Wu model are not sensitive to volume range in the analyzed local conditions, i.e. the deviations of the modeled and measured capacity are roughly equal in all load ranges.

Consequently, in terms of model reliability, the Akcelik model and the Brilon-Wu model better meet the criteria.

The mean absolute percentage error between the modeled capacity and the capacity directly measured in the field, shown in the following graphs and table, was used as an evaluation measure for model testing.

The mean absolute percentage error is calculated according to the following expression:

MAPE $=\frac{1}{n} \sum_{i=1}^{n}\left|\begin{array}{c}y_{\text {modeled }}-y_{\text {measured }} \\ y_{\text {measured }}\end{array}\right| * 100$

Table 2. Values of mean absolute error of modeled and measured capacity

\begin{tabular}{|c|c|c|c|}
\hline Capacity model & HCM 2010 & BRILON-WU & AKCELIK \\
\hline $\begin{array}{c}\text { Mean absolute percentage error } \\
\text { (MAPE) }\end{array}$ & 34.55 & $\mathbf{2 1 . 9 2}$ & 27.37 \\
\hline
\end{tabular}

According to the obtained estimates in Table 2, preference is given to the Brilon-Wu capacity model over the other two selected models. It resulted in smallest deviations in relation to the directly measured capacity, so this model proved to be applicable in the analyzed local conditions.

\section{CONCLUSION}

Considering the large number of existing roundabout capacity models, it is necessary to perform testing of models with directly measured capacity in specific conditions, in order to analyze their application in the specific conditions. 
Maslać, D., Cvitanić, D.

Comparison of capacity models of different theoretical settings on the example of a small city roundabout in the City of Mostar

In this paper, testing of the three selected most commonly used roundabout capacity models (HCM 2010, Akcelik and Brilon-Wu) was performed. All three models have different theoretical backgrounds.

Based on the directly measured capacity, it was established that the application of the Brilon-Wu model gives the results closest to the directly measured capacity in the analyzed local conditions in Bosnia and Herzegovina (small urban roundabout). The model is reliable with respect to overall volume ranges and has a good theoretical background based on conflict theory and queuing theory. In addition, this model provides the opportunity to analyze pedestrians and cyclists, which is especially important in urban environments.

\section{REFERENCES}

1. Luttinen,T.: Capacity at Unsignalized Intersections, TL Research Report No. 3, 2003.

2. Smjernice za projektiranje kružnih raskrižja na državnim cestama, Rijeka, srpanj 2014.

3. Wu, N.: A universal formula for calculating capacity at roundabouts, Arbeitsblaetter, Institute for traffic Engineering, Ruhr, University Bochum 1997

4. Jonsons T. Mark: Synthesis of roundabout geometric capacity measurement; calibration and validation to US field measurements, 92nd TRB Annual Meeting, 2013.

5. Highway Capacity Manual, Volume 3: Interrupted flow, TRB, Washington, 2010.

6. Troutbeck R., Brilon W.: Theory of traffic flow- Chapter 8, Unsignalized intersection theory, 8.1-8.47, 1997

7. Cvitanić, D.: Modeliranje kapaciteta i razine usluge nesemaforiziranih raskrižja, magistarski rad, 2000.

8. Cvitanic, D., Lozić, I.: Modeli kapaciteta nesemaforiziranih raskrizja, Ceste i mostovi, broj 7-8, str. 167-176, 2002.

9. Akcelik, R.: An Assessment of the Highway Capacity Manual 2010 Roundabout Capacity Model, International Roundabout Conference, Transportation Research Board, Carmel, Indiana, USA, 18-20 May 2011.

10. Akcelik, R.: An Assessment of the Highway Capacity Manual 6 Roundabout Capacity Model, 5th International Roundabout Conference, Transportation Research Board, Wisconsin, USA, 2017.

11. Akcelik, R.: Gap acceptance modeling by traffic signal analogy, Traffic Engineering and Control, 35 (9), pp. 498-506, 1994.

12. Brilon, W., Wu, N.: Capacity at unsignalized intersections derived by conflict technique, Transportation Research Record, No. 1776, p. 82 - 90, 2001

13. Brilon, W., Wu N.: Capacity at unsignalized two-stage priority intersections, Transportation Research Part A, Volume 33, Issues 3-4, Pages 275-289, 1999

14. Wu, N., Brilon W.: Roundabout Capacity Analysis Based on Conflict Technique, Teach Amerika, 2017.

15. $\mathrm{Wu}, \mathrm{N}$.: A universal procedure for capacity Determination at unsignalized (prioritycontrolled) intersections, Transportation Research part B 35, Issue 3, 2001. 